\title{
The emergency intrauterine device: an endangered species
}

The use of the intrauterine device (IUD) as emergency contraception (EC) may be in danger of extinction. Is it still necessary now that hormonal EC is more widely available than ever before since its deregulation in 2001 from prescription-only medicine (POM) to pharmacy (P) status in the UK? Furthermore, the widespread development of Patient Group Directions has allowed nurses and other professionals to issue the POM without involving a doctor. Recent research supports simpler regimes for hormonal EC including $1.5 \mathrm{mg}$ levonorgestrel in a stat dose, thus reducing the risk of non-compliance, ${ }^{1}$ and relaxing of the 72-hour rule. ${ }^{2}$ Nevertheless, women remain ill-informed about access and timing ${ }^{3}$ or are influenced by other factors leading to under use of the method. ${ }^{4}$ Doctors in primary care perceive the provision of emergency IUDs as expensive in terms of time and effort, and may be logistically difficult. ${ }^{5}$

If 1000 women used an emergency IUD less than one would carry a risk of pregnancy. If 1000 women used hormonal EC somewhere between 15 and 30 would be pregnant. There is no doubt that the IUD is the most effective method of EC. ${ }^{6}$ It has a wider window for postcoital use, can be fitted up to 5 days after unprotected sex or up to 5 days from the earliest calculated day of ovulation, whichever is the longer. ${ }^{7}$ In addition, it offers reliable contraception from the moment of insertion onwards, potentially for many years, thus minimising the risk of unplanned pregnancy due to further episodes of user or method failure in the same or future cycles when the motivation to re-attend for hormonal treatment may be low.

A frequently raised concern with the use of the EC IUD is the growing awareness regarding sexually transmitted infections (STIs), in particular Chlamydia trachomatis. A recent study found a significantly higher incidence of Chlamydia in young women attending for EC compared to women attending for general contraception. ${ }^{8}$ The need for training and retaining the skills necessary to fit an IUD also form a barrier to its wider use. ${ }^{5}$ Do these obstacles push the EC IUD further along the road to extinction except in very select, specialist hands? Will the method be completely superseded by the perceived ease of distributing the less invasive, ever more simplified hormonal option?

But is it truly so much easier to provide hormonal methods? Ideally a consultation regarding EC should assess the risk of pregnancy and STIs in an open, nonjudgmental way. Testing for STIs should be carried out as appropriate. The availability of less invasive tests which are highly sensitive and capable of detecting very small numbers of pathogens soon after infection ${ }^{8}$ will hopefully increase uptake of testing and thus improve detection and treatment, irrespective of the chosen method of EC. Cover for Chlamydia can be given with a single-dose treatment. No consultation on EC is complete unless ongoing contraception has been discussed and provided if the woman wishes. The provision of an IUD can cover all these areas. The extra time required for the fitting may be balanced by the reduced likelihood of re-attendance for further episodes, or the need to explain the use of the pill or other methods, or dealing with the consequences of unplanned conception.

The implementation of the National Sexual Health Strategy 9 with its envisaged development of primary care settings providing Level 2 care $^{9}$ which includes insertion of IUDs provides an ideal opportunity to improve services. Locally adaptable referral pathways with direct and rapid access for women requesting to have EC IUDs fitted may thus improve availability and accessibility. Clinicians willing to offer Level 2 service may be more likely to have a positive attitude, be motivated and well trained, thus reducing the risks associated with IUD insertion.

The emergency IUD will never replace the hormonal option, but there will always be a group of women for whom this method is ideal - not just at the time of their need - but also for ongoing contraception. Women have a right to know of this much more effective option and providers have a responsibility to reflect on their own attitude towards IUDs 10 and to regularly update their knowledge and skills. The method also needs to be better publicised and presented in a more objective way that allows women to weigh up the advantages and disadvantages, even before they access services. On a local level, health care providers need to develop strategies to improve access at convenient times and locations, whether through new provision in specialist centres or via referral mechanisms across traditional boundaries between general practices, family planning clinics, and Primary Care Trusts.

Finally, these considerations should not distract from the fact that in the end the use of an emergency IUD should be the result of informed choice by the woman. At present we are still a long way from offering either full information or choice.

\section{Acknowledgement}

The author wishes to thank Anne Webb, Consultant in the Abacus Clinics for Contraception and Reproductive Health, Liverpool, UK, for her helpful comments.

Statements on funding and competing interests

Funding. None identified.

Competing interests. None identified.

Simone Reuter, MFFP

Lead Clinician, Doncaster Family Planning Service, Chequer Road, Doncaster DN1 2AD, UK. E-mail: Simone.Reuter@dsh.nhs.uk

References

1 Von Hertzen H, Piaggio G, Ding J, et al. Low dose mifepristone and two regimens of levonorgestrel for emergency contraception: a WHO multicentre randomised trial. Lancet 2002; 360: 1803-1810.

2 Ellertson C, Evans M, Ferden S, et al. When is too late? Extending the time limit for starting emergency contraceptive pills. Obstet Gynecol 2003 (in press).

3 Perslev A, Rorbye C, Boesen H, et al. Emergency contraception: knowledge and use among Danish women requesting termination of pregnancy. Contraception 2002; 66: 427-431.

4 Free C, Lee R M, Ogden J. Young women's accounts of factors influencing their use and non-use of emergency contraception: indepth interview study. BMJ 2002; 325: 1393-1396.

5 Reuter S. Barriers to the use of IUDs as emergency contraception. $\mathrm{Br}$ J Fam Plann 1999; 25: 63-68.

6 Trussell J, Ellertson C. Efficacy of emergency contraception. Fertil Contracept Rev 1995; 4: 8-11.

7 Faculty of Family Planning and Reproductive Health Care, Royal College of Obstetricians and Gynaecologists. Emergency Contraception: Recommendations for Clinical Practice. Guidance document, April 2000

8 Kettle H, Cay S, Brown A, Glasier A. Screening for Chlamydia trachomatis infection is indicated for women under 30 using emergency contraception. Contraception 2002; 66: 251-253.

9 Department of Health. National Strategy for Sexual Health and HIV. London: Department of Health, 2001.

10 Espey E, Ogburn T. Perpetuating negative attitudes about the intrauterine device: textbooks lag behind the evidence. Contraception 2002; 65: 389-395. 